\title{
THE RELATIONSHIPS BETWEEN DROUGHT INDICES (SPI, API) AND IN-SITU SOIL MOISTURE IN FORESTED HILLSLOPES
}

\author{
YONG-SEOK GWAK, YUN-TAE KIM, CHANG-HEE WON \& SOO-HYUN KIM \\ Disaster Prevention Research Division, National Disaster Management Research Institute, Korea
}

\begin{abstract}
Soil moisture is a critical variable in agriculture and is closely associated with meteorological drought. It is an important issue to estimate and characterize the variation of the soil moisture using the drought indices. In this study, the variation is examined to figure out the relationship between meteorological drought indices and the soil moisture monitored in the soil depths $10 \mathrm{~cm}, 30 \mathrm{~cm}$ and $60 \mathrm{~cm}$ at forested hillslopes for 3 years (2009-2011). For the drought indices, a standard precipitation index (SPI), with time scales of 1, 2, 3, 6 and 12 months, and an antecedent precipitation index (API) are used. As a result, the optimum time scale of SPI to the soil moisture is from 1 to 2 months, but it depends on the soil layers. The correlation coefficient of SPI in summer is higher than that in spring and fall. The SPI is not a good measure of the soil moisture; it is better to use API with the exponential reduction function at all soil layers. Particularly, API with consideration to the seasonal patterns of parameter (SAPI) could well delineate the variations of the soil moisture at all soil layers $(\mathrm{r}=0.80)$, better than API with a fixed parameter $(\mathrm{r}=0.70)$. The seasonal variation of the API's parameter at soil layers could be associated with the evapotranspiration (PET) and the soil hydrological properties such as soil transmissivity. The seasonal characteristics of the soil moisture along with soil layers in this study should be considered to indicate and manifest the soil moisture using the drought indices.

Keywords: soil moisture, drought indices, standard precipitation index (SPI), antecedent precipitation index (API), time scale, correlation coefficient.
\end{abstract}

\section{INTRODUCTION}

Unlike most natural hazards such as floods and earthquakes, droughts could not suddenly occur and be recognized easily. The drought is usually defined in three types; meteorological-, agricultural- and hydrological-drought. Meteorological-, agricultural-, and hydrologicaldroughts are frequently quantified by the shortage of rainfall, soil moisture, streamflow, and reservoir levels over a long time-period. Particularly, agricultural droughts have often influenced the crop production that is sensitive to the soil moisture.

The soil moisture has an important role to play in the interaction among rainfall, streamflow and plant's growth [1]-[3], which is also a crucial factor in water resources management, as well as the estimation of drought [4], [5].

The drought indices have been potential work as indicators of soil moisture through the relationships between drought indices and the soil moisture in various regions [6]-[10]. They have frequently used the standardized precipitation index (SPI) from climatic data [11] to examine as the commonly used drought indices. Recently, the antecedent precipitation index (API) is also used in characterizing the soil moisture [6], [12].

In this study, we focus on the following topics through the relationship between two drought indices (SPI, API) and in-situ soil moisture monitored at the soil depth of 10, 30, $60 \mathrm{~cm}$ for $3 y e a r s$ in forested hillslopes, Korea;

i). The characterization (correlativity, time scale) of the two drought indices indicating the soil moisture in soil layer depth.

ii). The importance of seasonal impacts (temperature, evapotranspiration) delineating the soil moisture with the drought indices. 
iii). Finding a hydrological interpretation for i), ii).

\section{DATA AND METHODS}

\subsection{Data acquisition}

The study area is located in the humid forested hillslope in Gyeonggi-do, Korea (Fig. 1). Annual precipitation is approximate $1300 \mathrm{~mm}$, average temperature is 11.5 Celsius degrees. The dominant soil texture is sandy loam, the range of soil depth is from 0.4 to $0.8 \mathrm{~m}$. The dominated vegetation type is deciduous trees (Quercus sp \& Carpinus $s p$ ). The average slope of the hillslope is 19 degrees. The average soil porosity is $59.2,47.6$, and $42.2 \%$ at 10,30 , $60 \mathrm{~cm}$ soil layers, which is decreased as soil depth (the general pattern of soil properties in forest).

The soil moisture data had been observed using the TDR monitoring system (Soilmoisture Equipment Corp. 2012) for each 10,30,60 cm soil layer at 21 points within the hillslope. The data are obtained in every 2 hours for 3years (2009-2011), that were averaged daily in order to match with the time scale of the drought indices. The precipitation data for the period was observed with tipping bucket at KoFlux tower which is located approximately 300 to $500 \mathrm{~m}$ far from study area. The SPI data could be provided with the Korea Meteorological Association (KMA), which is interpolated with the nearest weather stations from the study area during the long periods (more than 30 years) due to the assumption of SPI calculation processes.

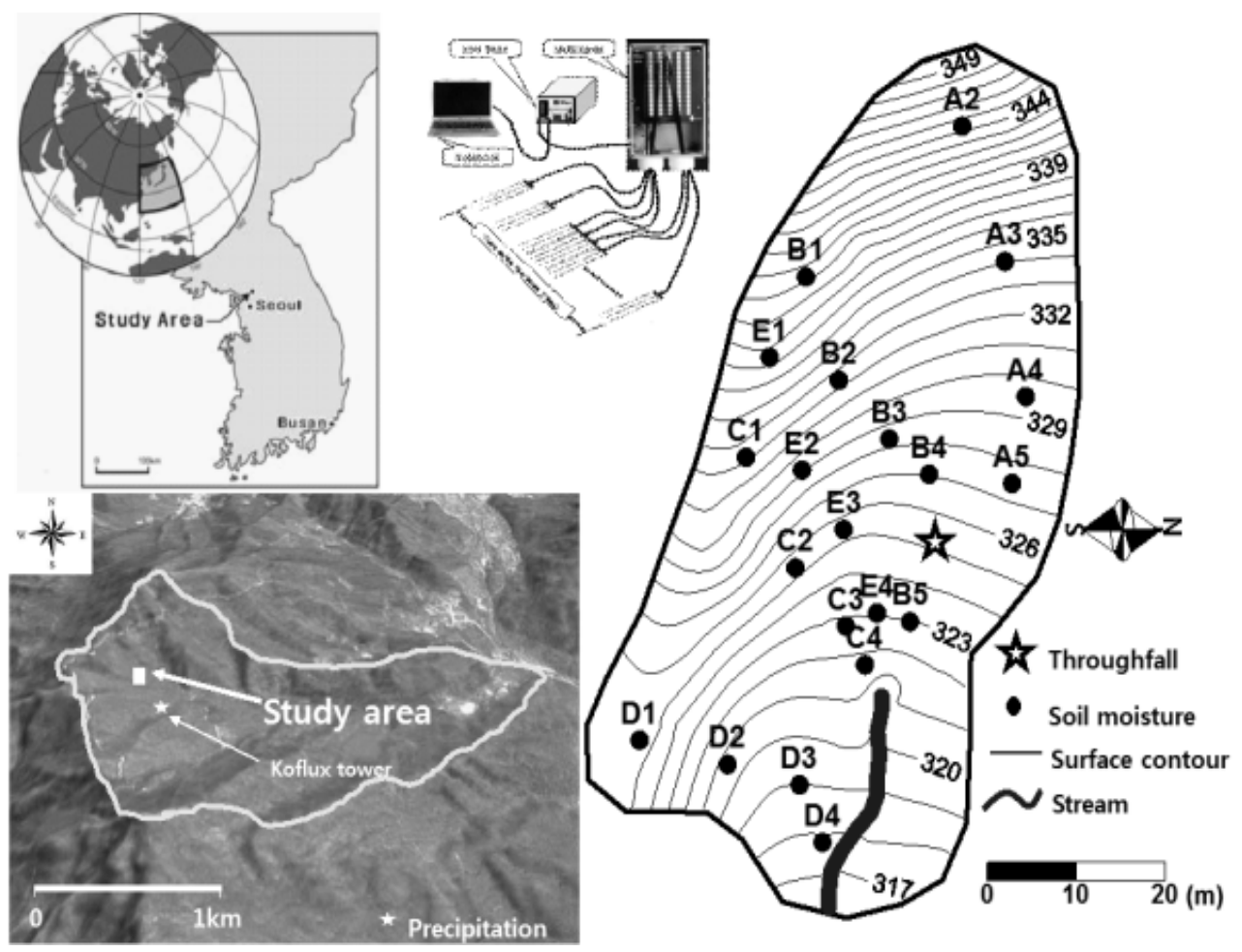

Figure 1: Locations of study area with the monitoring system of soil moisture. 


\subsection{The calculation of soil water and drought indices (SPI, API)}

To calculate the amount of the soil moisture(SM), it can be multiplied the thickness of each soil depth by the mean soil moisture of that layer.

$$
\begin{gathered}
S^{t}=\bar{\theta}^{t} \times L, \\
\bar{\theta}^{t}=\sum_{i=1}^{n} \theta_{i}^{t} / n,
\end{gathered}
$$

where $S$ is the amount of the soil moisture $(\mathrm{mm}), \theta$ is the observed volumetric soil moisture (\%). $\mathrm{L}$ is the thickness of each soil depth $(\mathrm{mm})$ and $\mathrm{n}$ is the number of the soil moisture monitoring point (21). We tried to identify the variations of the soil moisture in the soil layers by dividing the total soil depth $(0-80 \mathrm{~cm})$ into three soil layers; surface layer zone $(0-20 \mathrm{~cm})$, root zone $(20-45 \mathrm{~cm})$, subsurface zone $(45-80 \mathrm{~cm})$.

SPI (Standard Precipitation Index) is usually calculated in monthly to quantify the drought severity. In this study, however, the daily SPI could be computed and produced for the realtime drought monitoring (KMA). We appointed the time scale of SPI as 1 month (SPI1), 2months (SPI2), 3 months (SPI3), 6 months (SPI6), 1 year (SPI12). To calculate the daily SPI, the precipitation data was pre-processed as the following equation:

$$
P_{t}: \sum_{t-x}^{t} P_{i} \text { for' } 16-\mathrm{y}, \quad \sum_{t-x}^{t} P_{i} \text { for' } 16-\mathrm{y}+1, \ldots, \sum_{t-x}^{t} P_{i} \text { for '15, } \sum_{t-x}^{t} P_{i} \text { for'16, }
$$

where, $P_{t}$ is the accumulated precipitation data with the time scale $(\mathrm{x})$ on a certain day $(\mathrm{t})$ during y year. The data is transformed into the accumulated probability value by adapting a probability function (Person type-III), finally calculated into standard normal distribution value [11].

API (Antecedent Precipitation Index) is a running day by day measure of watershed wetness based on the rainfall that has happened over preceding days. The index has a hydrological concept that the antecedent precipitation impact decreases as the antecedent days increases. It could be defined in extended exponential function [6] as following:

$$
A P I_{t}=k A P I_{t-1}+P_{t}
$$

where, $A P I_{t}$ the antecedent precipitation index on a certain day $(\mathrm{t}), \mathrm{k}$ is an empirical decay parameter less than 1 (varied in environmental condition), and $P_{t}$ is rainfall for the day $(\mathrm{t})$. The parameter, $\mathrm{k}$ is usually used with 0.85 that is closely related with the seasonal pattern of evapotranspiration (from 0.85 to 0.98 ) [13], [14].

For analysing seasonal patterns of the drought indices and the monitored soil moisture, the seasons were classified into spring $\left(1^{\text {st }}\right.$ Mar. to $14^{\text {th }}$ June $)$, summer $\left(15^{\text {th }}\right.$ July to $14^{\text {th }}$ Sep.), and fall $\left(15^{\text {th }}\right.$ Sep. to $30^{\text {th }}$ Nov.) which were divided by the variations of temperature, rainfall, and soil moisture.

\subsection{The calculation of correlation coefficient}

The correlation coefficient between the drought indices and the soil moisture is calculated the following equation:

$$
\mathrm{CC}=\frac{\sum_{i=1}^{n}\left(S_{i}-\bar{S}\right)\left(D_{i}-\bar{D}\right)}{\sqrt{\sum_{i=1}^{n}\left(S_{i}-\bar{S}\right)^{2}} \cdot \sqrt{\sum_{i=1}^{n}\left(D_{i}-\bar{D}\right)^{2}}},
$$

where CC is person correlation coefficient, $\mathrm{S}$ and $\mathrm{D}$ are the data of the soil moisture and the drought indices (SPI, API). $\bar{S}, \bar{D}$ are the average of the soil moisture and the drought indices. The analysed soil moisture data is the value in eqn (1). 


\section{RESULTS AND DISCUSSION}

\subsection{Time series of the soil moisture, SPI, and API}

Fig. 2 shows the time series of the soil moisture at $10,30,60 \mathrm{~cm}$, rainfall and drought indices (SPI series with the time scales, API with the fixed parameter $(0.85)$ ). The amount of rainfall indicates the high in summer, low in winter, which has approximately $60 \%$ of total rainfall (1346, 1610, $2210 \mathrm{~mm} /$ year 2009 2011) for Jul. and Aug.

The soil moisture at soil layers dynamically varies with the occurrence of rainfall. In summer period, the frequent and intensive rainfall caused the increase of the soil moisture at all soil depths, while the soil moisture was not changed in spring season, rapidly decreases on average in fall rainless season. The omitted dataset of soil moisture was not observed because of the management of monitoring system in winter and the malfunction of device. As the time scale of SPI is increased, the fluctuations of it is decreased. SPI series show the discontinuous variation at a particular time of rainless periods while API presents the continuous variation.

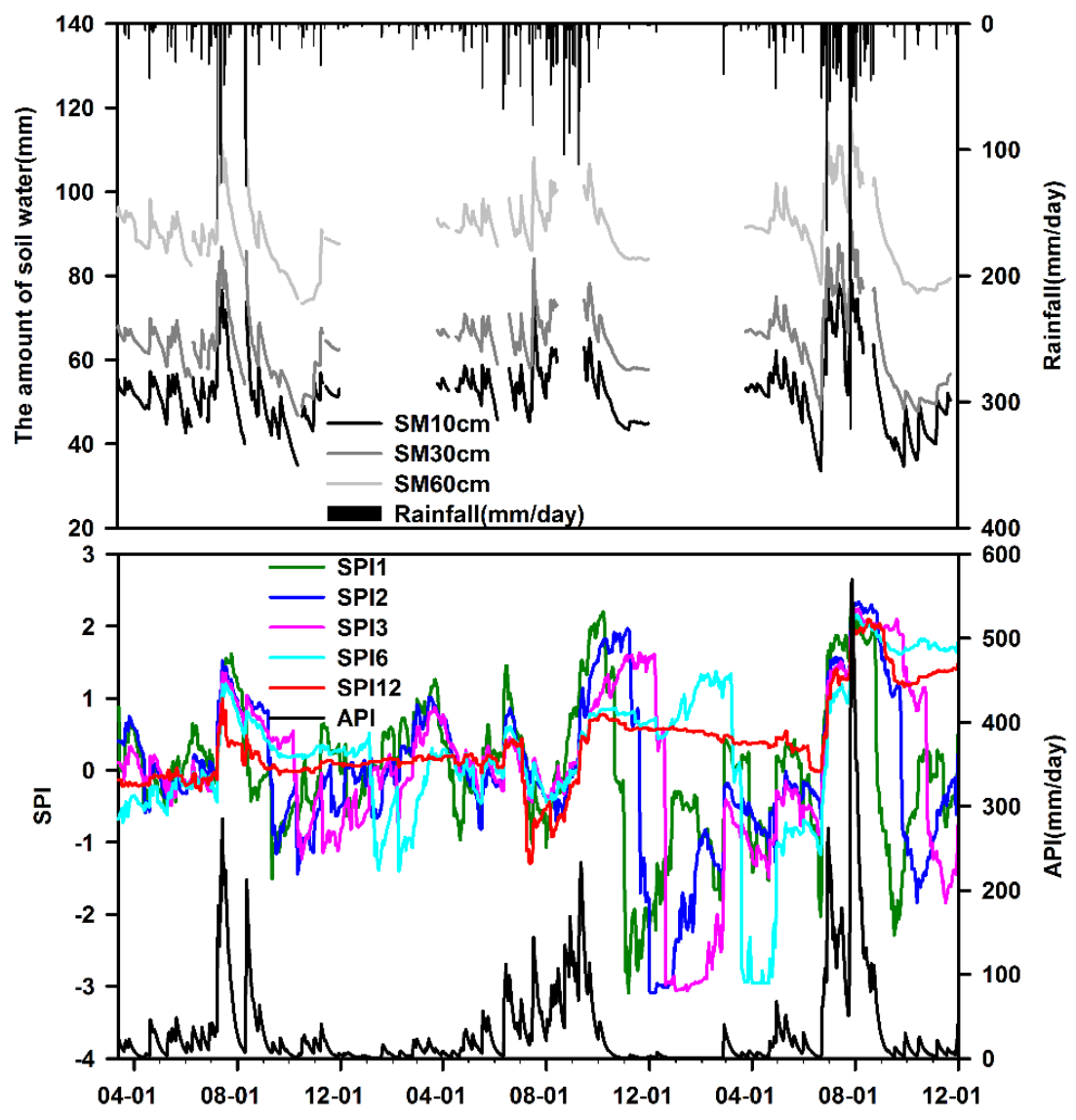

Figure 2: The daily variations of the soil moisture at 10, 30, 60 soil layers (above), SPI with the time scales $(1,2,3,6,12$ months), and API (bottom) in 3 years (20092011). 


\subsection{Correlation analysis}

Fig. 3 shows the correlation coefficients between the soil moisture and SPI series, API. The correlation coefficients of SPI series are less than 0.7, but that of API are more than 0.7 regardless of soil layers. Therefore, API could delineate the variation of the soil moisture more than SPI series. This may be caused by the different reduction patterns that SPI has a suddenly discontinuous reduction while API has a continuously exponential reduction. The exponential reduction of API could be explained by the physical movement of the soil moisture; the soil moisture is rapidly decreased by the gravity via macropore at early drainage stage, slowly decreased by the evapotranspiration and soil tension via soil matrix after the gravity drainage process [15], [16].

Among SPI series, the correlation coefficient of SPI1, SPI2 are higher compared with those of SPI3, SPI6, and SPI12. This means that the variation of the soil moisture is related with the history of precipitation for a short period. However, as deeper soil layers, the correlation coefficients of SPI1 are decreased while those of SPI2, SPI3 are increased. These results could explain that the variation of the soil moisture at a deep soil depth may be related with the longer time scale of SPI. These results are also founded in the other research [8]. They show that the optimal time scale of SPI to the time variation of the soil moisture at 0 $5 \mathrm{~cm}$ soil depth was 1 to 3 months while that at $90 \mathrm{~cm}$ soil depth was $6-12$ months. These results have a hydrological implication that the time scale of antecedent rainfall events influence the variation of the soil moisture, which may be related with the increasing mean residence time of the soil moisture at soil layers [17].

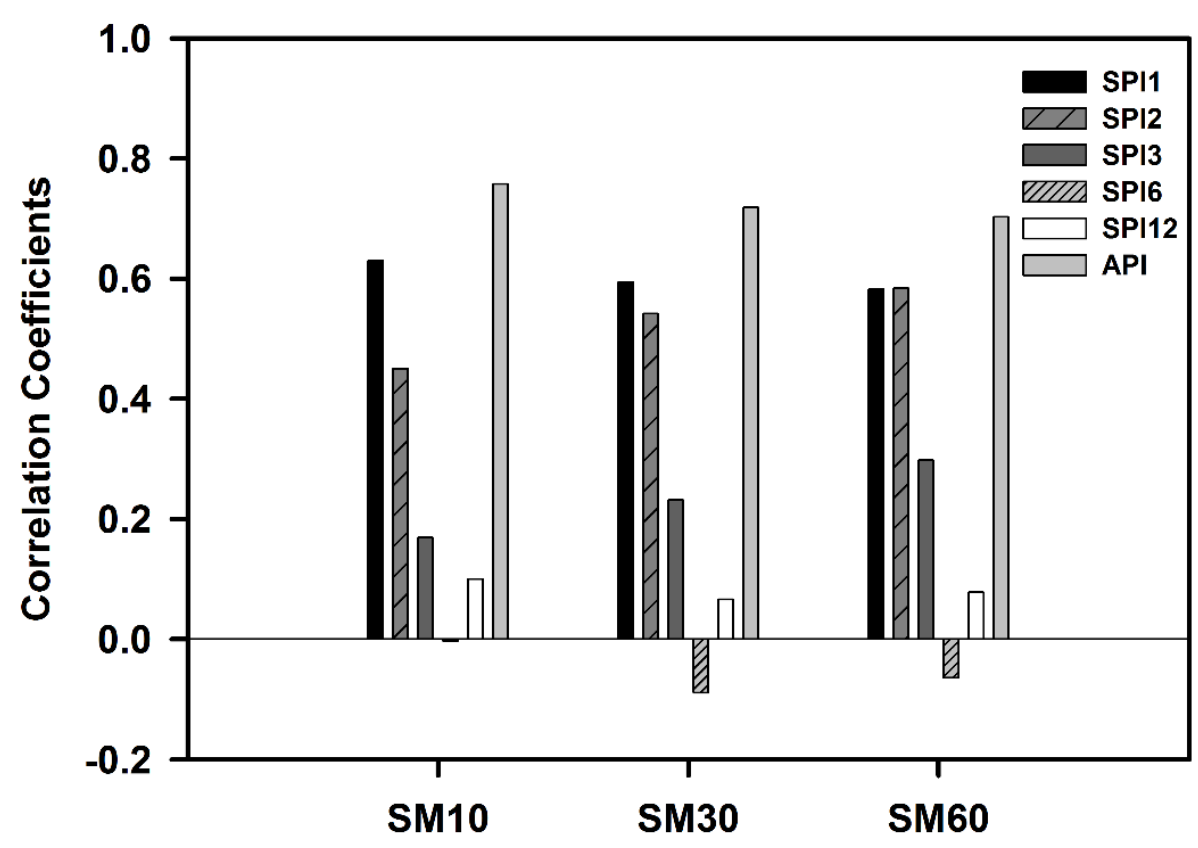

Figure 3: The correlation coefficients between the drought indices (SPI with the several time scales and API) and the soil moisture at soil layers for 3 years. 
Table 1: The seasonal variations of correlation coefficients between the soil moisture and drought indices (SPI with the several time scales, API) in $10,30,60 \mathrm{~cm}$ soil layers.

\begin{tabular}{cccccccc}
\hline Soil moisture & Seasons & SPI1 & SPI2 & SPI3 & SPI6 & SPI12 & API \\
\hline \hline \multirow{3}{*}{ SM10 } & Spring & 0.13 & 0.14 & 0.15 & -0.06 & $0.40^{*}$ & $0.59^{*}$ \\
& Summer & $0.70^{*}$ & $0.50^{*}$ & $0.41^{*}$ & $0.40^{*}$ & $0.33^{*}$ & $0.79^{*}$ \\
& Fall & $0.68^{*}$ & $0.46^{*}$ & -0.04 & 0.03 & 0.09 & $0.67^{*}$ \\
\hline \multirow{3}{*}{ SM30 } & Spring & 0.07 & 0.08 & 0.06 & -0.17 & $0.47^{*}$ & $0.52^{*}$ \\
& Summer & $0.71^{*}$ & $0.56^{*}$ & $0.47^{*}$ & $0.46^{*}$ & $0.40^{*}$ & $0.81^{*}$ \\
& Fall & $0.48^{*}$ & $0.72^{*}$ & $0.32^{*}$ & 0.03 & 0.10 & $0.42^{*}$ \\
\hline \multirow{3}{*}{ SM60 } & Spring & 0.20 & 0.15 & 0.13 & -0.05 & $0.46^{*}$ & $0.61^{*}$ \\
& Summer & $0.69^{*}$ & $0.58^{*}$ & $0.51^{*}$ & $0.49^{*}$ & $0.43^{*}$ & $0.81^{*}$ \\
& Fall & $0.39^{*}$ & $0.77^{*}$ & $0.49^{*}$ & $0.18^{*}$ & $0.26^{*}$ & $0.33^{*}$ \\
\hline
\end{tabular}

*Indicates a significant level of $1 \%$ probability.

\subsection{The seasonal correlation coefficients between SM and the drought indices}

The seasonal correlation coefficients are shown in Table 1. The coefficients in summer are higher than those in fall, spring, regardless of the soil layers and drought indices. At $10 \mathrm{~cm}$ soil depth in summer, the coefficients are higher than those that deep soil layers, since the fast infiltration and drainage of the soil moisture may be occurring for intensive rainfall events. Interestingly, the coefficients of SPI 2 at $30,60 \mathrm{~cm}$ soil depths in fall are higher than those in summer. The increases of the coefficients of SPI2 in fall present that the mean residence time of the soil moisture is longer compared with those in spring, summer. These results mean that the seasonal variations of the soil moisture at soil depths have been considered in order to describe the soil moisture using drought indices.

\subsection{The correlation coefficients between SM and API considering seasonal patterns (SAPI)}

According to confirming the seasonal time scales of drought indices (SPI), we applied to estimate API with considering seasonal patterns (SAPI). The monthly empirical parameters (k) of API were optimized through the iteration processes to obtain the high correlation coefficient between API and SM for one year. As a result, the correlation coefficients of SAPI were $0.800,0.791,0.786$ at 10,30 , and $60 \mathrm{~cm}$ soil layers, which were significantly increased compared with those of API (Table 1). This result clearly shows that it is much better to consider the seasonal patterns of drought indices in order to delineate the soil moisture. Wang [8] presented that the SPI with considering the evapotranspiration works similarly or better than the SPI in characterizing the soil moisture.

Fig. 4 presents the monthly optimum parameters $(\mathrm{k})$ at soil layers and the estimated evapotranspiration (PET) by Thornthwaite method in 2009. The variations of the parameter (k) from 0.81 to 0.98 have an inverse relationship with the PET. This definitely shows that the parameters of API are related to PET. Besides, as deeper soil layer, the minimum values of parameters are increased. The reduction rate of soil moisture is decreased with deep soil 
depth [15]. Therefore, we strongly suggest that the modelling the soil moisture with the drought indices needs to consider the seasonal pattern of drought indices (the time scales of SPI, monthly parameter of API) and the reduction patterns of the soil moisture at the soil depths.

\section{CONCLUSIONS}

This study examined with relationship which the drought indices (SPI with several time scales, API, SAPI) in characterizing the observed soil moisture variations at a humid forested hillslope and identified the hydrological understandings of the seasonal variations of the soil moistures. We found and concluded the following three terms:

1) API could describe the variations of the soil moisture at the soil layers (surface, root, subsurface zone) much better than SPI. This fits well may be attributed to the exponential reduction rate and continuous variations of API, while the time series of SPIs is discontinuous compared with that of API.

2) Although SPI is not good to delineate the in-situ soil moisture, the variations of correlation coefficients with several time scales show that the optimum time scale could be different at the soil layers. It seems to be related with the mean residence time of the soil moisture caused by the soil transmissivity in soil depths.

3) Considering the seasonal patterns of the empirical parameters of API, the correlation coefficients of SAPI are significantly increased compared with those of API. This indicates that the seasonal factors such as evapotranspiration need to be considered in characterizing soil moisture.

The results will definitely contribute to understand the hydrological implications of the characterization of the drought indices. It will be researched in several environmental conditions (such as other climate regions, soil texture) in order to enhance and figure out the possibility to delineate the soil moisture with the drought indices.

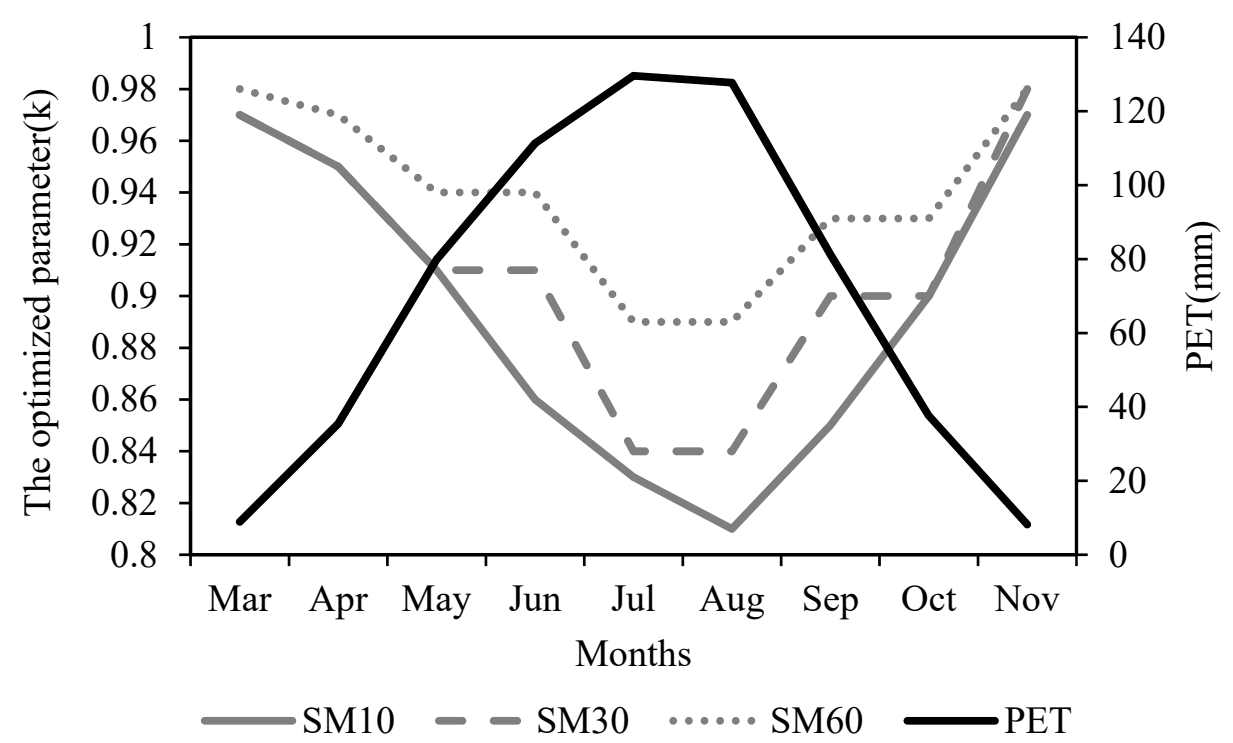

Figure 4: The monthly variation of the optimized parameter of API at the soil layers and the evapotranspiration calculated by Thornthwaite at the study area in 2009 . 


\section{REFERENCES}

[1] Fedora, M.A. \& Beschta, R.L., Storm runoff simulation using an antecedent precipitation index (API) model. Journal of Hydrology, 112(1-2), pp. 121-133, 1989.

[2] Rodriguez-Iturbe, I. \& Porporato, A., Ecohydrology of water controlled ecosystems: soil moisture and plant dynamics, Cambridge University Press: Cambridge, UK, 2004.

[3] Tromp-van Meerveld, H.J. \& McDonnell, J.J., On the interrelations between topography, soil depth, soil moisture, transpiration rates and species distribution at the hillslope scale. Advances in Water Resources, 29, pp. 293-310, 2006

[4] Brooca, L., Melone, F. \& Moramarco, T., On the estimation of antecedent wetness conditions in rainfall-runoff modelling. Hydrological Processes, 22, pp. 629-642, 2008.

[5] Sohrabi, M.J., Ryu, J., Abatzoglou, J. \& Tracy, J., Development of soil moisture drought index to characterize droughts. Journal of Hydrologic Engineering (ASCE), 2015. 10.1061/(ASCE)HE. 1943-5584.0001213, 04015025.

[6] Brooca, L., Melone, F. \& Moramarco, T., Empirical and conceptual approaches for soil moisture estimation in view of event-based rainfall-runoff modelling. Progress in surface and subsurface water studies at the plot and small basin scale, F. Maraga and M. Arattano, eds, IHP-VI technical Documents in Hydrology, 77, UNESCO, Paris, pp. $1-8,2005$.

[7] Hao, Z. \& AghaKouchak, A., Multivariate standardized drought index: A parametric multi-index model. Advances in Water Resources, 57, pp. 12-18, 2013.

[8] Wang, H., Rogers, J.C. \& Munroe, D.K., Commonly used drought indices as indicators of soil moisture in China. Journal of Hydrometeorology, 16(3), pp. 1397-1408, 2015.

[9] Weng et al., Drought assessment in the Dongliao River Basin: traditional approaches vs. generalized drought assessment index based on water resources systems. Natural Hazards and Earth System Sciences, 15, pp. 1889-1906, 2015.

[10] Zhao, Y., Wei, F., Yang, H. \& Jiang, Y., Discussion on using antecedent precipitation index to supplement relative soil moisture data series. Procedia Environmental Sciences, 10, pp. 1489-1495, 2011.

[11] McKee, T.B., Doesken, N.J. \& Kleist, J., The relationship of drought frequency and duration to time scales. Preprints. Eighth Conf. on Applied Climatology, Anaheim, CA, Boston, MA, American Meteorological Society, pp. 179-184, 1993.

[12] McQuigg, J., A simple index of drought conditions. Weatherwise, 7, pp. 64-67, 1954.

[13] Cordery, I., Antecedent wetness for design flood estimation. Civil engineering Transactions CE, 12(2), pp. 181-184.

[14] Saxton, K.E. \& Lenz, A.T., Antecedent retention indexes predict soil moisture. Journal of Hydraulics Division, 93, pp. 223-244, 1967.

[15] Beven, K.J. \& Germann, P., Macropores and water flow in soils. Water Resources Research, 18(5), pp.1311-1325, 1982.

[16] Beven, K.J. \& Germann, P., Macropores and water flow in soils revisited. Water Resources Research, 49(6), pp. 3071-3092, 2013.

[17] Uchida, T., Mcdonnell, J.J. \& Yuko, A., Functional inter comparison of hillslopes and small catchments by examining water sources, flowpath and mean residence time. Journal of Hydrology, 327, pp. 627-642. 